\title{
Validation of a Finite Element Approach to Modeling of Structural Collapse of Steel Structures
}

\author{
Vitaliy V. Saykin ${ }^{1}$, Tam H. Nguyen ${ }^{2}$, Jerome F. Hajjar ${ }^{3}$, Derya Deniz ${ }^{4}$, Junho Song ${ }^{5}$ \\ ${ }^{1}$ Graduate Research Assistant, Department of Civil and Environmental Engineering, Northeastern \\ University, 400 Snell Engineering Center, 360 Huntington Ave, Boston, MA 02115; PH (781) \\ 521-3395; email: v.saykin@neu.edu \\ ${ }^{2}$ Postdoctoral Research Associate, Department of Civil and Environmental Engineering, \\ Northeastern University, 400 Snell Engineering Center, 360 Huntington Ave, Boston, MA 02115; \\ PH (781) 521-3395; email: th.nguyen@neu.edu \\ ${ }^{3}$ Professor and Chair, Department of Civil and Environmental Engineering, Northeastern \\ University, 400 Snell Engineering Center, 360 Huntington Ave, Boston, MA 02115; Office (617) \\ 373-3242; Cell (617) 794-7844;FAX (617) 373-4419; email: jf.hajjar@neu.edu \\ ${ }^{4}$ Graduate Research Assistant, Department of Civil and Environmental Engineering, University of \\ Illinois, 2207 Newmark Civil Engineering Laboratory, 205 N. Mathews Ave., Urbana, IL 61801; \\ Office (217) 333-4311; email: ddeniz2@illinois.edu \\ ${ }^{5}$ Associate Professor, Department of Civil and Environmental Engineering, Seoul National \\ University, Gwanangno 599, Gwanakgu, Seoul, 151-744, Republic of Korea; email: \\ junhosong@gmail.com
}

\begin{abstract}
The prediction of collapse of structures has gained growing attention recently, as it is important to be able to predict and model structural collapse due to extreme loads. A lack of accurate and validated structural collapse models significantly limits the structural engineering community to predict possible extreme loads that precipitate collapse. This paper proposes an integrated platform for validated prediction of collapse of steel structures that accounts for material softening followed by elimination of finite elements to enable simulation of fracture. The proposed approach employs a Void Growth Model (VGM) to simulate the initiation of softening and the Hillerborg model for modeling the softening itself, followed by an element deletion strategy that is developed in this framework. The parameters of these models were calibrated to a comprehensive set of experimental test results of circumferentially notched tensile (CNT) coupon specimens. These calibrated models were then validated through comparison with a broad array of experimental test results of steel structures, ranging in complexity from tensile coupons to moment-resisting beam-to-column connections. The proposed approach is shown to be accurate. Through element deletion, the formulation can account for complete structural component separation, thus precipitating modeling of the collapse of structures. This approach thus enables high-fidelity parametric simulation capabilities of interest to researchers, practitioners, and code developers who address collapse of structures.
\end{abstract}

\section{INTRODUCTION}

In recent years the collapse of steel structures such as Wedbush Building due to a construction accident (Mercury News 2013), and the structural collapses during the 1994 Northridge (Cooper et al. 1994) and 1995 Kobe earthquakes (Miyazaki et al. 2013) have 
highlighted the limitation of knowledge and understanding of structural behavior of steel structures undergoing progressive or disproportionate collapse (Khandelwal 2008; Szyniszewski et al. 2012). One factor that makes studying structural collapse difficult is the lack of full-scale structural collapse experimental test results against which researchers could validate their proposed collapse modeling approaches. In addition, a lack of accurate and validated structural collapse models limits the options for design against disproportionate collapse within the structural engineering community. This paper proposes an integrated platform for validated prediction of collapse of steel structures that accounts for material softening followed by elimination of finite elements to enable simulation of fracture and complete separation in steel members.

\section{COLLAPSE MODELING USING ELEMENT DELETION APPROACH}

To properly model collapse of steel structures using finite element analysis, one needs to properly account for material separation. In this paper, the Void Growth Model (VGM) and a damage model, called the Hillerborg Model hereafter, that are available in ABAQUS finite element software were used to account for fracture initiation in within finite elements and its subsequent deletion of the elements through material softening (ABAQUS 2011). The material nonlinear formulation is developed in conjunction with using a von Mises yield surface with associated plastic flow and isotropic hardening behavior. An updated Lagrangian geometrical nonlinear element formulation that includes large strains is also used (ABAQUS 2011). Elements are formulated in the current configuration using current nodal positions. Contact was modeled using a balanced master-slave contact pair formulation that uses sophisticated tracking algorithms for tracking the motions of the surfaces (ABAQUS 2011). Contact constraints are enforced through a kinematic contact algorithm (ABAQUS 2011).

Fracture initiation is modeled in ABAQUS through the VGM, a phenomenological model of fracture initiation due to void nucleation, growth, and coalescence inside the ductile material (Rice et al. 1969). A fundamental assumption of the model is that the critical equivalent plastic strain is a function of stress triaxiality expressed by Equations (1) and (2):

$$
\begin{gathered}
T=\frac{\sigma_{m}}{\bar{\sigma}} \\
\bar{\varepsilon}_{\mathrm{FI}}^{\mathrm{pl}}(\mathrm{T})=\eta \mathrm{e}^{-\beta \mathrm{T}}
\end{gathered}
$$

where:

- $T$ - triaxiality

- $\sigma_{\mathrm{m}}-$ mean stress

- $\bar{\sigma}-$ von Mises equivalent stress

- $\bar{\varepsilon}_{\mathrm{FI}}^{\mathrm{pl}}(\mathrm{T})$ - critical equivalent plastic strain at fracture initiation

- $\beta$-material property constant

- $\eta$-material capacity constant

The criteria for fracture initiation is met when the integral of the ratio of the equivalent plastic strain at an integration point of the element to the critical equivalent plastic strain as a function of triaxiality equals 1, expressed by Equation (3) (Hooputra et al. 2004): 


$$
\int \frac{d \bar{\varepsilon}^{p l}}{\bar{\varepsilon}_{F I}^{p l}(T)}=1
$$

For calibration and validation, triaxiality, equivalent plastic strain, and other stress-strain related properties are calculated at the integration point of each finite element. The value of this integral would increase at each increment of the analysis monotonically with plastic deformation. Upon reaching a value of 1.0, the fracture initiation criteria is met and material softening subsequently takes place (ABAQUS 2011). Void coalescence in a finite element is then represented by softening of an element. Softening of the element is modeled through a Hillerborg Model (Hillerborg et al. 1976). The damage manifests itself through softening of the yield surface and degradation of elasticity modeled by Equation (4) and Equation (5), respectively:

where:

$$
\begin{gathered}
\bar{\sigma}_{S}=(1-D) * \bar{\sigma}_{N S} \\
E_{S}=(1-D) * E
\end{gathered}
$$

- $\bar{\sigma}_{S}$ - equivalent stress with softening accounted for

- $\bar{\sigma}_{N S}-$ equivalent stress with no softening being modeled

- $D$-damage variable

- $E_{s}-$ Elastic modulus modified to account for softening

- $E-$ Elastic modulus

$\bullet$

During softening, spatial mesh dependency is introduced based on strain localization, which causes dissipated energy to decrease as the mesh is refined (ABAQUS 2011). A stress-displacement relationship has thus been proposed in the literature to mitigate localization (Hillerborg et al. 1976). This is achieved through defining a material parameter that describes the energy required to open a unit area of crack, $G_{f}$. The fracture energy is then given by Equation (6).

$$
G_{f}=\int_{\bar{\varepsilon}_{F I}^{p l}}^{\bar{\varepsilon}_{f}^{p l}} L \sigma_{y} d \bar{\varepsilon}^{p l}=\int_{0}^{\bar{u}_{f}^{p l}} \sigma_{y} d \bar{u}^{p l}
$$

where:

- $G_{f}$ - fracture energy

- $\bar{\varepsilon}_{F I}^{p l}$ - equivalent plastic strain at fracture initiation

- $\bar{\varepsilon}_{f}^{p l}, \bar{u}_{f}^{p l}$ - equivalent plastic strain, displacement at element deletion, respectively

- $L$ - characteristic length

- $\sigma_{y}-$ yield stress

The characteristic length, $L$, depends on the element geometry and formulation (ABAQUS 2011). The equivalent plastic displacement is a fracture work conjugate to the yield stress after the onset of softening. Before fracture initiation $\bar{u}^{p l}=0$, and after fracture initiation $\bar{u}^{p l}=\int L d \bar{\varepsilon}^{p l}$. The relationship between the equivalent plastic displacement and the damage parameter, $D$, was chosen to be linear for all of the simulations in this paper after performing numerous simulations 
and comparing the softening curve of the simulations to the experimental ones. The damage variable, $D$, is defined by Equation (7):

$$
D=\frac{\bar{u}^{p l}}{\bar{u}_{f}^{p l}}
$$

The critical equivalent plastic displacement at which $D$ equals 1 has to be provided. In this work, when this is reached at an integration point of an element, the element is deleted. By allowing for monotonically decreasing stress and stiffness during softening, this approach, in addition to mitigating spatial mesh dependency, allows for minimizing spurious transient effects of dynamic instabilities upon element deletion that may cause inaccuracy of the results. This is due to the fact that element stiffness and stress are brought to zero through a linear relationship defined by Equations (4), (5), and (7), thus avoiding abrupt changes in element stiffness and stress and the resulting transient dynamic response. Figure 1Figure 1 shows the Hillerborg model, where the damage parameter, $D$, equals 0 at fracture initiation and it increases monotonically to 1 through Equation (7), at which point the element is deleted. Variable $\bar{\sigma}_{F I}$ is the equivalent stress at fracture initiation.

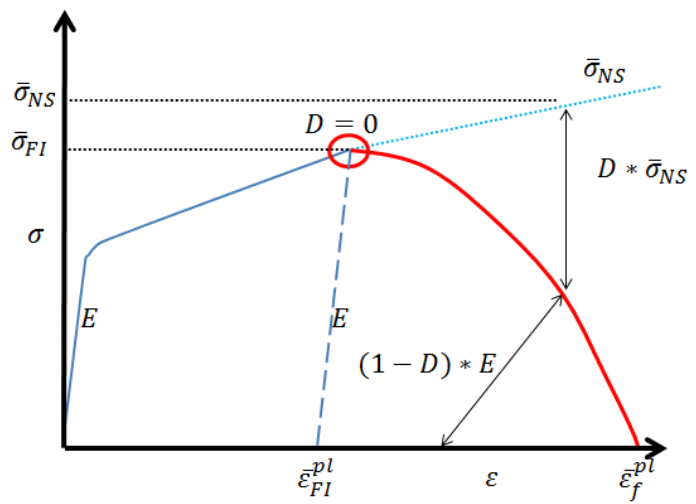

Figure 1: Hillerborg model relation of equivalent stress versus equivalent strain at an integration point of an element

\section{PARAMETER CALIBRATION}

For calibration, a model of the circumferential notched tensile (CNT) coupon specimen was created in ABAQUS using 8 node hexahedral elements with first-order interpolation and reduced integration. The nominal flow property used for each of the steels is a piece-wise linear fit to the measured true stress-strain curve obtained from the experimental test results (Kanvinde et al. 2004). Each material was calibrated to experimental test results from CNTs with different root notch sizes. This allowed for calibration of fracture initiation for a particular material at a range of triaxiality. Triaxiality is varied in CNT by the root notch size which ranged from 0.06 to 0.25 inches; the smaller the notch radii, the larger the triaxiality if the root diameter is kept constant.

The parameters that need to be calibrated for this approach are $\eta$ the material capacity, $\beta$ the material parameter, and $\bar{u}_{f}^{p l}$ the critical equivalent plastic displacement; these parameters are seen in Equations ( 2 and (7. The mesh of the finite element models was typically refined to have 
a maximum element size of 0.02 inches to account for different boundary conditions at critical locations such as notches in CNTs.

To achieve best fit calibration of the simulation results to experimental test results a particle swarm optimization (PSO) algorithm was employed. PSO is a computational method that optimizes a problem by iteratively improving solution with regard to a given measure of quality, such as a target value of an error quantity (Kennedy 1997). PSO proposes values for the parameters and runs the simulation. It compares the simulation with the experimental test results and provides an error value which it uses to assess the quality of the parameters chosen and determine the global and local best position (Smith et al. 2013). The error value is calculated by Equation (8). For subsequent runs the PSO updates the calibrating parameters through updating the velocity by Equation (9) and the position by Equation (10) of each of the parameters:

where:

$$
e r r=\frac{\Delta E}{E_{e x}}
$$

- $\Delta E-$ the difference between the total energy of simulation and experimental (or other established) results

- $E_{\text {ex }}-$ the total energy of the experimental (or other established) results

where:

$$
\begin{gathered}
v_{i}(k+1)=\varphi(k) v_{i}(k)+\alpha_{1} \gamma_{1}\left(p_{i}-x_{i}(k)\right)+\alpha_{2} \gamma_{2}\left(G-x_{i}(k)\right) \\
x_{i}(k+1)=x_{i}(k)+v_{i}(k+1)
\end{gathered}
$$

- $i$ - particle index

- $k$-discrete time index

- $v$ - velocity of $\mathrm{i}^{\text {th }}$ particle

- $x$ - position of the $\mathrm{i}^{\text {th }}$ particle

- $\quad p$-best position found by the $\mathrm{i}^{\text {th }}$ particle (personal best)

- $G$ - best position found by swarm (global best, best of personal bests)

- $\gamma_{1,2}$ - random numbers on the interval $[0,1]$ applied to ith particle

- $\varphi-$ Inertia function

- $\alpha 1,2-$ Acceleration constants

For each simulation, an error value from Equation (8) for a set of parameters is compared to the global best parametrical set that has the lowest error value. If it is smaller than the global best, it keeps the values of the parameters as the optimal ones. PSO goes through this process for each particle position and iteration. This process continues until satisfactory results are obtained, which are defined by the lowest error value for all of the runs.

Using this approach, the calibrated structural steels, their parameters, and associated information about the original experimental tests are provided in Table 1 and Table 2 . In these tables, $D_{U N}$ is the unnotched root diameter, $D_{N}$ is the diameter at the notch, $R_{N}$ is the radius of the notch, and $\Delta_{f}$ is the displacement at which fracture initiation occurred. Figure 2 shows calibration results for A572 Grade 50 steel taken from a wide flange section. Figure 3 shows the calibration results for JIS-SN490B Grade 50 taken from a plate section. Calibration results for other structural 
steels are similar with a mean error value and standard deviation being, respectively, 0.127 and 0.029 for American steels and 0.077 and 0.01 for Japanese steels.

Table 1: Calibration of the structural steels commonly used in North America ranging from low yield to high yield including bridge steel is shown

\begin{tabular}{|c|c|c|c|c|c|c|c|c|c|c|c|c|}
\hline & & & & & & & & & & arame & ers & err \\
\hline Author & Test & $\begin{array}{c}\text { Material } \\
\text { Type }\end{array}$ & $\begin{array}{l}D_{U N} \\
\text { (in) }\end{array}$ & $\begin{array}{l}D_{N} \\
\text { (in) }\end{array}$ & $\begin{array}{l}R_{N} \\
\text { (in) }\end{array}$ & $\begin{array}{c}\sigma_{y} \\
(\mathbf{k s i})\end{array}$ & $\begin{array}{c}\sigma_{u} \\
(\mathbf{k s i})\end{array}$ & $\begin{array}{c}\Delta_{f} \\
\text { (in) }\end{array}$ & $\eta$ & $\beta$ & $\overline{\boldsymbol{u}}_{f}^{p l}(\mathrm{in})$ & \\
\hline \multirow{8}{*}{$\begin{array}{l}\text { (Myers et } \\
\text { al. 2009) }\end{array}$} & 1 & \multirow{8}{*}{ A36 } & 0.500 & 0.248 & 0.126 & \multirow{8}{*}{50} & \multirow{8}{*}{74} & 0.067 & \multirow{8}{*}{4.17} & \multirow{8}{*}{2.79} & \multirow{8}{*}{0.0068} & \multirow{8}{*}{0.187} \\
\hline & 2 & & 0.496 & 0.252 & 0.126 & & & 0.067 & & & & \\
\hline & 3 & & 0.500 & 0.252 & 0.126 & & & 0.067 & & & & \\
\hline & 4 & & 0.496 & 0.252 & 0.126 & & & 0.066 & & & & \\
\hline & 5 & & 0.496 & 0.248 & 0.063 & & & 0.050 & & & & \\
\hline & 6 & & 0.496 & 0.248 & 0.063 & & & 0.051 & & & & \\
\hline & 7 & & 0.492 & 0.248 & 0.063 & & & 0.051 & & & & \\
\hline & 8 & & 0.500 & 0.252 & 0.063 & & & 0.051 & & & & \\
\hline \multirow{3}{*}{$\begin{array}{l}\text { (Myers et } \\
\text { al. 2009) }\end{array}$} & 1 & \multirow{3}{*}{ A992 } & 0.504 & 0.252 & 0.067 & \multirow{3}{*}{54} & \multirow{3}{*}{114} & 0.047 & \multirow{3}{*}{1.00} & \multirow{3}{*}{2.04} & \multirow{3}{*}{0.0041} & \multirow{3}{*}{0.091} \\
\hline & 2 & & 0.508 & 0.248 & 0.067 & & & 0.043 & & & & \\
\hline & 3 & & 0.508 & 0.252 & 0.067 & & & 0.044 & & & & \\
\hline \multirow{3}{*}{$\begin{array}{l}\text { (Myers et } \\
\text { al. 2009) }\end{array}$} & 1 & \multirow{3}{*}{ A992 } & 0.496 & 0.244 & 0.067 & \multirow{3}{*}{54} & \multirow{3}{*}{114} & 0.037 & \multirow{3}{*}{1.00} & & & \\
\hline & 2 & & 0.496 & 0.244 & 0.067 & & & 0.039 & & 2.04 & 0.0041 & 0.091 \\
\hline & 3 & & 0.496 & 0.248 & 0.067 & & & 0.038 & & & & \\
\hline & 1 & & 0.689 & 0.244 & 0.067 & & & 0.025 & & & & \\
\hline (Myers et & 2 & A992 & 0.685 & 0.244 & 0.067 & 54 & 114 & 0.026 & 1.25 & 2.40 & 0.0048 & 0.132 \\
\hline & 3 & & 0.685 & 0.244 & 0.067 & & & 0.020 & & & & \\
\hline & 1 & & 0.500 & 0.252 & 0.126 & & & 0.056 & & & & \\
\hline & 2 & A572- & 0.500 & 0.252 & 0.126 & & & 0.074 & & & & \\
\hline (Kanvinde & 3 & Grade 50 & 0.500 & 0.252 & 0.126 & 61 & 77 & 0.074 & 110 & 000 & 00076 & 0009 \\
\hline et al. & 6 & from W- & 0.500 & 0.252 & 0.059 & 61 & 72 & 0.044 & 1.19 & 0.99 & $0.00 / 6$ & 0.098 \\
\hline & 7 & section & 0.500 & 0.252 & 0.059 & & & 0.042 & & & & \\
\hline & 8 & & 0.500 & 0.252 & 0.059 & & & 0.047 & & & & \\
\hline & 1 & & 0.500 & 0.252 & 0.126 & & & 0.041 & & & & \\
\hline & 2 & & 0.500 & 0.252 & 0.126 & & & 0.033 & & & & \\
\hline (Kanvinde & 3 & A572- & 0.500 & 0.252 & 0.126 & & & 0.037 & & & & \\
\hline et al. & 4 & Grade 50 & 0.500 & 0.252 & 0.059 & 56 & 85 & 0.022 & 2.95 & 3.79 & 0.0068 & 0.131 \\
\hline 2004) & 5 & from & 0.500 & 0.252 & 0.059 & & & 0.024 & & & & \\
\hline & 6 & & 0.500 & 0.252 & 0.252 & & & 0.049 & & & & \\
\hline & 7 & & 0.500 & 0.252 & 0.252 & & & 0.050 & & & & \\
\hline & 1 & & 0.500 & 0.252 & 0.126 & & & 0.028 & & & & \\
\hline & 2 & & 0.500 & 0.252 & 0.126 & & & 0.027 & & & & \\
\hline (Kanvinde & 3 & A514- & 0.500 & 0.252 & 0.059 & 116 & 124 & 0.016 & 185 & 175 & 00070 & 0120 \\
\hline et al. & 4 & Grade & 0.500 & 0.252 & 0.059 & 116 & 124 & 0.013 & 1.85 & 1.75 & 0.0028 & 0.128 \\
\hline & 5 & & 0.500 & 0.252 & 0.252 & & & 0.053 & & & & \\
\hline & 6 & & 0.500 & 0.252 & 0.252 & & & 0.039 & & & & \\
\hline & 1 & & 0.500 & 0.252 & 0.126 & & & 0.066 & & & & \\
\hline (Kanvinde & 2 & HDC $70 \Psi$ & 0.500 & 0.252 & 0.126 & 85 & 101 & 0.055 & 445 & 266 & 00102 & 0120 \\
\hline & 3 & HPS70W & 0.500 & 0.252 & 0.059 & 85 & 101 & 0.034 & 4.45 & 2.00 & 0.0102 & 0.120 \\
\hline & 4 & & 0.500 & 0.252 & 0.059 & & & 0.033 & & & & \\
\hline & & & & & & & & & & Mean & Error $=$ & 0.127 \\
\hline & & & & & & & & & Stanc & $\operatorname{ard} D$ & iation $=$ & 0.029 \\
\hline
\end{tabular}


Table 2: Calibration of structural steels commonly used in Japan

\begin{tabular}{|c|c|c|c|c|c|c|c|c|c|c|c|c|}
\hline & & & & & & & & & & arame & ers & err \\
\hline Author & Test & $\begin{array}{c}\text { Material } \\
\text { Type }\end{array}$ & $\begin{array}{l}D_{U N} \\
\text { (in) }\end{array}$ & $\begin{array}{l}D_{N} \\
\text { (in) }\end{array}$ & $\begin{array}{l}R_{N} \\
\text { (in) }\end{array}$ & $\begin{array}{c}\sigma_{\mathbf{y}} \\
(\mathrm{ksi})\end{array}$ & $\begin{array}{c}\sigma_{\mathrm{u}} \\
(\mathrm{ksi})\end{array}$ & $\begin{array}{c}\Delta_{f} \\
\text { (in) }\end{array}$ & $\eta$ & $\beta$ & $\bar{u}_{f}^{p l}$ (in) & \\
\hline \multirow{4}{*}{$\begin{array}{l}\text { (Kanvind } \\
\text { e et al. } \\
\text { 2004) }\end{array}$} & 1 & \multirow{4}{*}{$\begin{array}{c}\text { JIS- } \\
\text { SN490B } \\
\text { Grade 50 }\end{array}$} & 0.500 & 0.252 & 0.126 & \multirow{4}{*}{47.6} & \multirow{4}{*}{74.7} & 0.061 & \multirow{4}{*}{1.00} & \multirow{4}{*}{0.83} & \multirow{4}{*}{0.0078} & \multirow{4}{*}{0.064} \\
\hline & 2 & & 0.500 & 0.252 & 0.126 & & & 0.064 & & & & \\
\hline & 3 & & 0.500 & 0.252 & 0.059 & & & 0.043 & & & & \\
\hline & 4 & & 0.500 & 0.252 & 0.059 & & & 0.049 & & & & \\
\hline \multirow{4}{*}{$\begin{array}{c}\text { (Kanvind } \\
\text { e et al. } \\
2004 \text { ) }\end{array}$} & 1 & JIS- & 0.500 & 0.252 & 0.126 & \multirow{4}{*}{59.9} & \multirow{4}{*}{74.9} & 0.092 & \multirow{4}{*}{1.47} & \multirow{4}{*}{0.84} & \multirow{4}{*}{0.0083} & \multirow{4}{*}{0.084} \\
\hline & 2 & $\begin{array}{l}\text { SM490Y } \\
\text { BTMC- }\end{array}$ & 0.500 & 0.252 & 0.126 & & & 0.092 & & & & \\
\hline & 3 & 5L Grade & 0.500 & 0.252 & 0.059 & & & 0.060 & & & & \\
\hline & 4 & 50 & 0.500 & 0.252 & 0.059 & & & 0.056 & & & & \\
\hline \multirow{4}{*}{$\begin{array}{l}\text { (Kanvind } \\
\text { e et al. } \\
2004 \text { ) }\end{array}$} & 1 & JIS- & 0.500 & 0.252 & 0.126 & \multirow{4}{*}{49.1} & \multirow{4}{*}{69.0} & 0.089 & \multirow{4}{*}{1.36} & \multirow{4}{*}{0.79} & \multirow{4}{*}{0.0083} & \multirow{4}{*}{0.084} \\
\hline & 2 & \multirow{3}{*}{$\begin{array}{l}\text { Grade } 50 \\
\text { from W- } \\
\text { section }\end{array}$} & 0.500 & 0.252 & 0.126 & & & 0.091 & & & & \\
\hline & 3 & & 0.500 & 0.252 & 0.059 & & & 0.051 & & & & \\
\hline & 4 & & 0.500 & 0.252 & 0.059 & & & 0.055 & & & & \\
\hline & & & & & & & & & \multirow{2}{*}{\multicolumn{3}{|c|}{$\begin{array}{r}\text { Mean Error }= \\
\text { Standard Deviation }=\end{array}$}} & 0.077 \\
\hline & & & & & & & & & & & & 0.010 \\
\hline
\end{tabular}
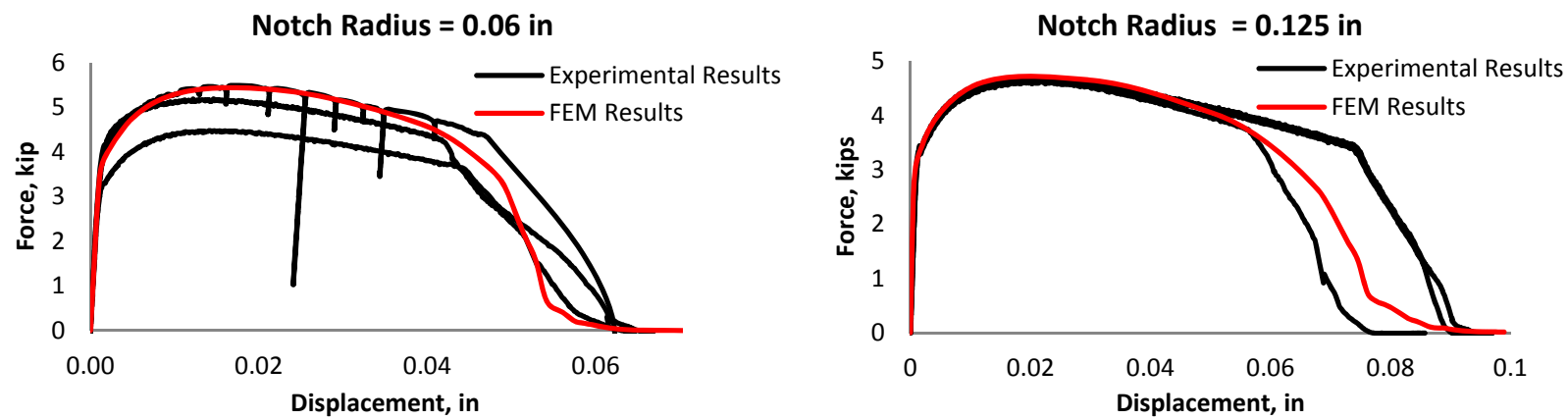

Figure 2: Calibration results of $\mathrm{A572}$ Grade 50 steel CNT with notch radius of 0.06 inches (left) and 0.125 inches (right) with error value of 0.0984
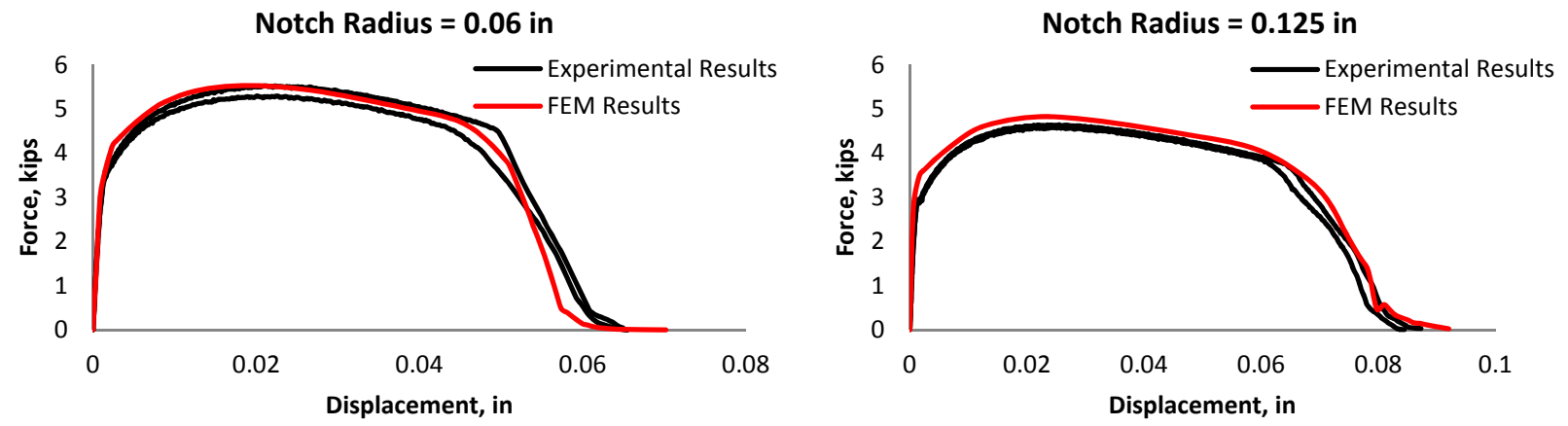

Figure 3: Calibration results of JIS-SN490B Grade 50 steel CNT with notch radius of 0.06 inches (left) and 0.125 inches (right) with error value of 0.0635 


\section{VALIDATION}

After the parameters of the VGM and Hillerborg models were calibrated for a particular steel based on the use of CNT specimens, they were validated through comparison with a broad array of experimental test results of steel structures, ranging in complexity from tensile coupons to moment-resisting beam-to-column connections. The list of validation simulations is provided in Table 3. The calibrated parameters were validated in ABAQUS software using an 8 node hexahedral elements with first-order interpolation and reduced integration (i.e., comparable modeling assumptions as were stated for the calibration studies). For each particular steel, the plasticity model was identical to the one used in calibration for which the nominal flow properties were a piece-wise linear fit to the measured true stress-strain curve obtained from the experimental test results. The mesh of finite element models varied from simulation to simulation but met certain criteria. For each simulation, the meshing size was judged adequate to properly account for boundary conditions when a finer mesh of finite elements gave similar results. In addition, critical structural components were meshed with at least two elements through its thickness to account for stress gradients. The error value used to compare simulation results with experimental test results given Equation (8) is provided for each simulation, with the overall mean error being 0.220 and standard deviation of 0.078 . Figure 4 to Figure 6 show typical validation results and fracture location comparisons.
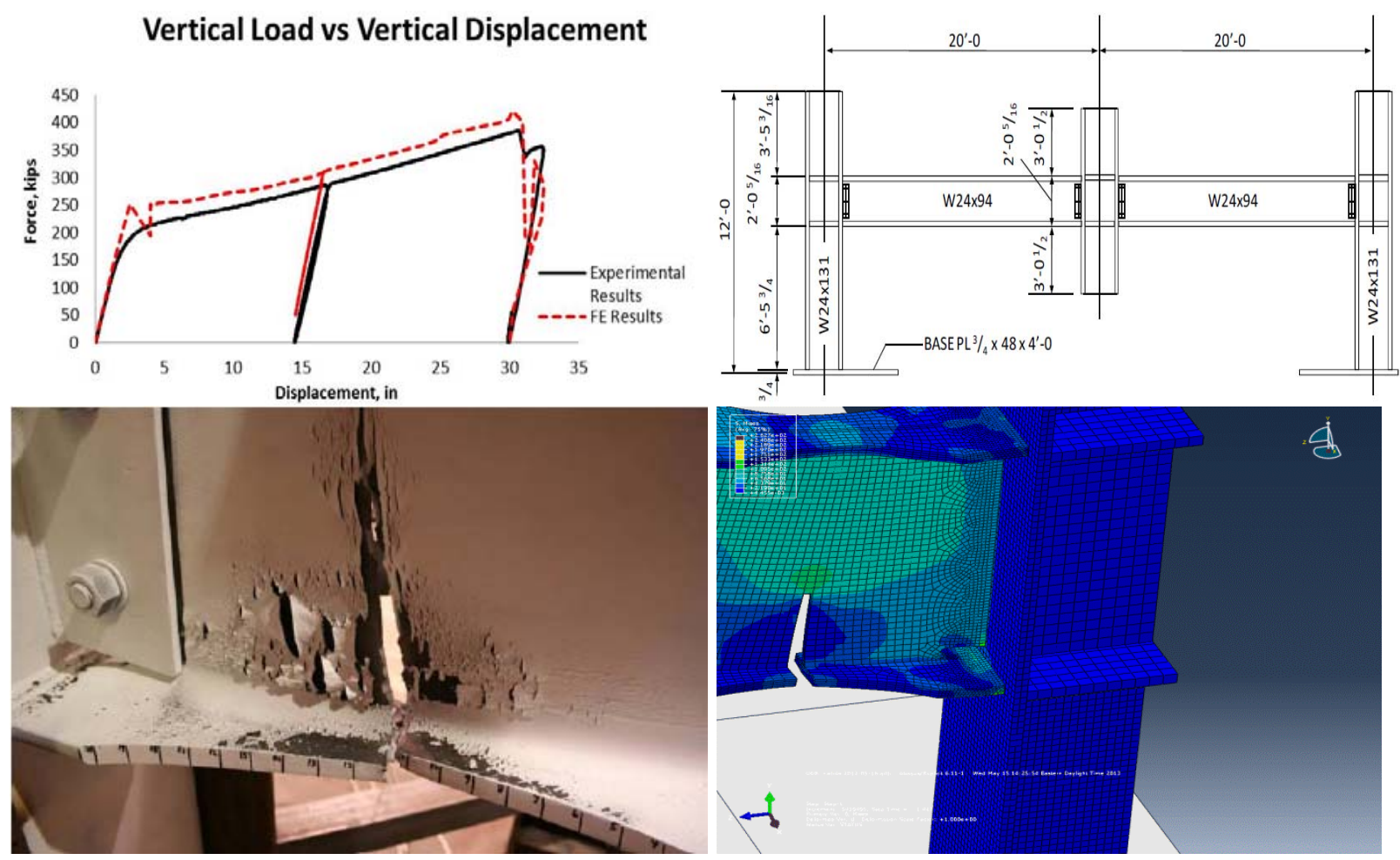

Figure 4: Force-displacement plot of validation results versus experimental (upper left), the experimental layout of RBS sub-assemblage frame with central column loaded in a downward direction (upper right), fracture location in the reduced beam section during experiment (lower left), and FEM simulation results (right) with contours representing von Mises stress (Sadek et al. 2010) 

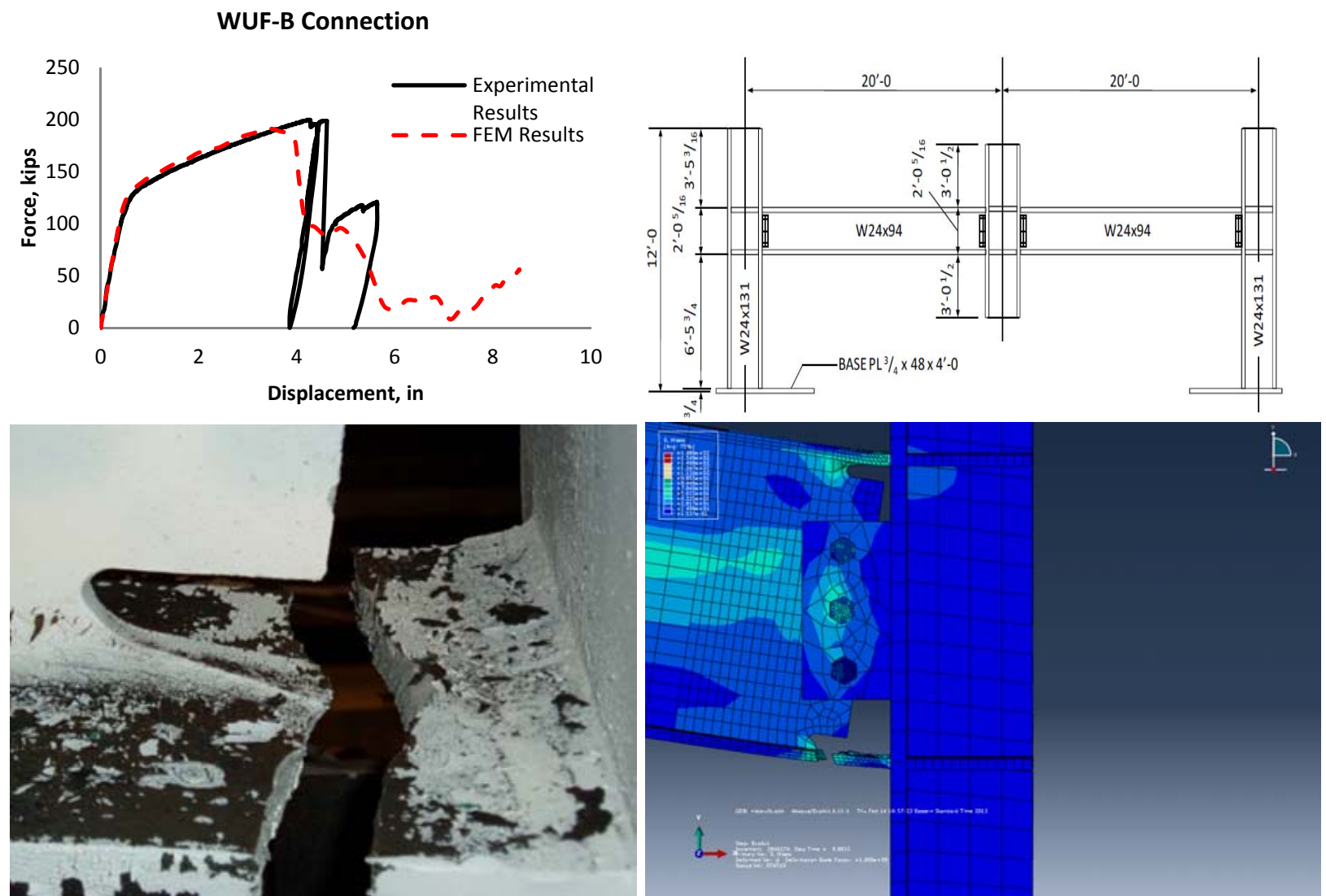

Figure 5: Force-displacement plot of validation results versus experimental (upper left), the experimental layout of WUF-B sub-assemblage frame with central column loaded in a downward direction (upper right), fracture location in the bottom beam flange during experiment (lower left), and FEM simulation results (right) with contours representing von Mises stress (Sadek et al. 2010)
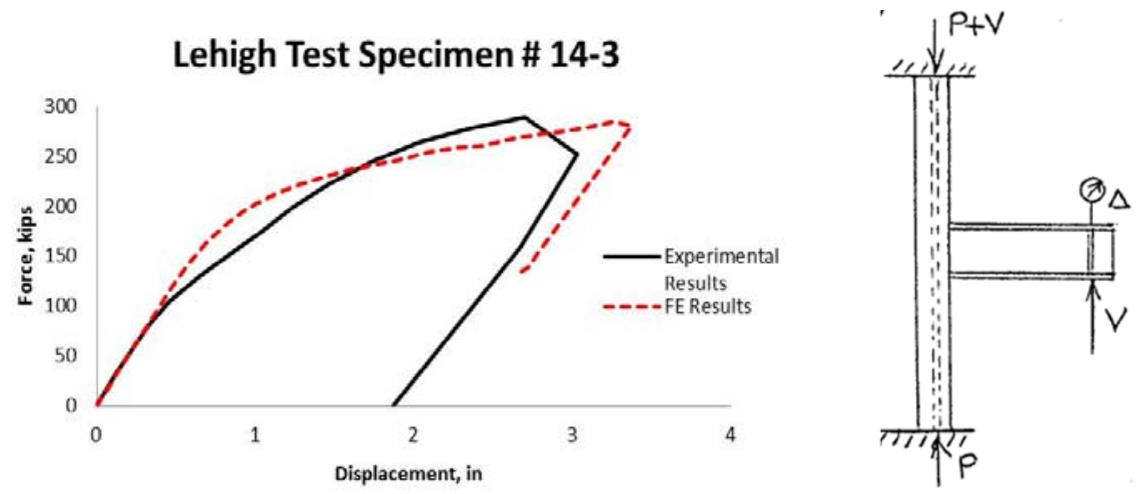

Figure 6: Force vs. displacement plot of validation results versus experimental (right), the experimental layout of the moment resisting beam to column connection (Rentschler et al. 1978) 
Table 3: Results of validation studies

\begin{tabular}{|c|c|c|c|c|c|c|c|}
\hline Author & Test Type & Test & Material Type & $\sigma_{\mathrm{y}}(\mathrm{ksi})$ & $\sigma_{u}(k s i)$ & $\Delta_{f}$ (in) & err \\
\hline \multirow{4}{*}{$\begin{array}{l}\text { (Myers et } \\
\text { al. 2009) }\end{array}$} & \multirow{4}{*}{ CNT } & 9 & \multirow{4}{*}{ A36 } & \multirow{4}{*}{50} & \multirow{4}{*}{74} & 0.038 & \multirow{4}{*}{0.327} \\
\hline & & 10 & & & & 0.043 & \\
\hline & & 11 & & & & 0.042 & \\
\hline & & 12 & & & & 0.041 & \\
\hline \multirow{4}{*}{$\begin{array}{l}\text { (Myers et } \\
\text { al. 2009) }\end{array}$} & \multirow{4}{*}{ CNT } & 13 & \multirow{4}{*}{ A36 } & \multirow{4}{*}{50} & \multirow{4}{*}{74} & 0.021 & \multirow{4}{*}{0.278} \\
\hline & & 14 & & & & 0.024 & \\
\hline & & 15 & & & & 0.024 & \\
\hline & & 16 & & & & 0.023 & \\
\hline \multirow{3}{*}{$\begin{array}{l}\text { (Myers et } \\
\text { al. 2009) }\end{array}$} & \multirow{3}{*}{ CNT } & 17 & \multirow{3}{*}{ A36 } & \multirow{3}{*}{50} & \multirow{3}{*}{74} & 0.036 & \multirow{3}{*}{0.189} \\
\hline & & 18 & & & & 0.036 & \\
\hline & & 19 & & & & 0.037 & \\
\hline \multirow{4}{*}{$\begin{array}{l}\text { (Myers et } \\
\text { al. 2009) }\end{array}$} & \multirow{4}{*}{ CNT } & 20 & \multirow{4}{*}{ A36 } & \multirow{4}{*}{50} & \multirow{4}{*}{74} & 0.020 & \multirow{4}{*}{0.215} \\
\hline & & 21 & & & & 0.025 & \\
\hline & & 22 & & & & 0.025 & \\
\hline & & 23 & & & & 0.031 & \\
\hline \multirow{3}{*}{$\begin{array}{l}\text { (Kanvinde } \\
\text { et al. 2004) }\end{array}$} & \multirow{3}{*}{ Plate - BH } & 1 & A572-Gr. 50 & 56 & 85 & 0.140 & 0.210 \\
\hline & & 1 & HPS70W & 85 & 101 & 0.148 & \multirow{2}{*}{0.320} \\
\hline & & 2 & HPS70W & 85 & 101 & 0.138 & \\
\hline & & 1 & A572-Gr. 50 & 56 & 85 & 0.246 & 0.156 \\
\hline (Kanvinde & Plate RBS & 1 & HPS70W & 85 & 101 & 0.203 & 0178 \\
\hline & & 2 & HPS70W & 85 & 101 & 0.216 & $0.1 / 8$ \\
\hline & & 1 & A572-Gr. 50 & 56 & 85 & 0.109 & \\
\hline & & 2 & A572-Gr. 50 & 56 & 85 & 0.120 & 0.125 \\
\hline (Kanvinde & Compact & 3 & A572-Gr. 50 & 56 & 85 & 0.105 & \\
\hline et al. 2004) & Tension & 1 & A572-Gr. 50 & 61 & 72 & 0.422 & \\
\hline & & 2 & A572-Gr. 50 & 61 & 72 & 0.409 & 0.071 \\
\hline & & 3 & A572-Gr. 50 & 61 & 72 & 0.404 & \\
\hline (Kanvinde & 3 Pt. & 1 & A572-Gr. 50 & 61 & 72 & 0.122 & 0.11 \\
\hline et al. 2004) & Bending & 2 & A572-Gr. 50 & 61 & 72 & 0.163 & 0.112 \\
\hline $\begin{array}{l}\text { (Birkemoe } \\
\text { et al. 1978) }\end{array}$ & $\begin{array}{c}\text { Double } \\
\text { Angle Con. }\end{array}$ & 1 & $\begin{array}{l}\text { CSA G40.21- } \\
44 \mathrm{~W}\end{array}$ & 53 & 79 & 1.020 & 0.332 \\
\hline & & 14-1 & A572-Gr. 50 & 61 & 72 & 2.103 & 0.213 \\
\hline et al 1978) & Non & $14-2$ & A572-Gr. 50 & 61 & 72 & 1.641 & 0.223 \\
\hline & & $14-3$ & A572-Gr. 50 & 61 & 72 & 3.031 & 0.312 \\
\hline (Sadek et & RBS & 1 & A992 & 54 & 114 & 31.700 & 0.189 \\
\hline al. 2010) & WUF-B & 1 & A992 & 54 & 114 & 18.400 & 0.298 \\
\hline & & & & & & Error $=$ & 0.220 \\
\hline
\end{tabular}

\section{CONCLUSION}

In this study, the Void Growth Model is used in conjunction with the Hillerborg Model to model fracture initiation and softening of finite elements at integration point accurately using ABAQUS finite element software. Once stress and stiffness are degraded through softening the element is deleted. This is done by first calibrating the parameters of the mentioned models and then using those calibrated parameters to simulate other experimental tests. Since the Hillerborg model is based on equivalent plastic displacement, this approach is mesh independent as long as the mesh is fine enough to properly account for boundary conditions of the problem. Therefore, the proposed approach is shown to be accurate, and through element deletion, the formulation can 
account for complete structural component separation thus precipitating modeling of the collapse of steel structures. Researchers, practitioners, and code developers who address collapse could use this approach to perform high-fidelity parametric simulation to study structural behavior of steel structures during collapse.

\section{ACKNOWLEDGEMENT}

This material is based upon work supported by the National Science Foundation under Grant No. CMMI-1000666, Northeastern University, and the University of Illinois at Urbana-Champaign. This work used the Extreme Science and Engineering Discovery Environment (XSEDE), which is supported by National Science Foundation grant number OCI-1053575. Any opinions, findings and conclusions or recommendations expressed in this material are those of the authors and do not necessarily reflect the views of the National Science Foundation.

\section{REFERENCES}

ABAQUS 6.11 (2011). Abaqus User Manual, Dassault Systèmes Simulia Corp., Providence, Rhode Island.

Birkemoe, P. C., and Gilmore, M. I. (1978). "Behavior of Bearing Critical Double-Angle Beam Connections,” Engineering Journal, 4(15), 109-115.

Cooper, J. D., Friedland, I. M., Buckle, I. G., Nimis, R. B., and Bobb, N. M. (1994). The Northridge Earthquake: Progress Made, Lessons Learned in Seismic-Resistant Bridge Design, 58, U.S. DOT Federal Highway Administration, Washington, D.C.

Hillerborg, A., Modeer, M., and Petersson, P. E. (1976). “Analysis of Crack Formation and Crack Growth in Concrete by Means of Fracture Mechanics and Finite Elements," Cement and Concrete Research, 6(6), 773-782.

Hooputra, H., Gese, H., Dell, H., and Werner, H. (2004). “A Comprehensive Failure Model for Crashworthiness Simulation of Aluminium Extrusions," International Journal of Crashworthiness, 5(9), 449-464.

Kanvinde, A. M., and Deierlein, G. G. (2004). Micromechanical Simulation of EarthquakeInduced Fracture in Steel Structures, Report \# 145, The John A. Blume Earthquake Engineering Center, Stanford, California.

Kennedy, J. (1997). "The Particle Swarm: Social Adaptation of Knowledge," Proceeding of the IEEE International Conference on Evolutionary Computation 1997, IEEE, Washington, D.C., 303-308.

Khandelwal, K. (2008). "Multi-Scale Computational Simulation of Progressive Collapse of Steel Frames," Ph.D. Dissertation, University of Michigan, Ann Arbor, Michigan.

Mercury (2013). “5 Floors of Building Collapse,” San Jose Mercury News, San Jose, California. 
Myers, A. T., Deierlein, G. G., and Kanvinde, A. (2009). Testing and Probabilistic Simulation of Ductile Fracture Initiation in Structural Steel Components and Weldments, Report \# 170, The John A. Blume Earthquake Engineering Center, Stanford, California.

Rentschler, G. P., Chen, W.-F., and Driscoll, G. C. (1978). Tests of Beam-to-Column Web Moment Connections, Report \# 405.9, Fritz Engineering Laboratory, Bethlehem, Pennsylvania.

Rice, J. R., and Tracey, D. M. (1969). "On the Ductile Enlargement of Voids in Triaxial Stress Fields," Journal of the Mechanics and Physics of Solids, 3(17), 201-217.

Sadek, F., Main, J. A., Lew, H. S., Robert, S. D., Chiarito, V. P., and El-Tawil, S. (2010). An Experimental and Computational Study of Steel Moment Connections under a Column Removal Scenario, NIST Technical Note 1669, National Institute of Standards and Technology, U.S. Department of Commerce, Gaithersburg, Maryland.

Smith, C. M., Kanvinde, A. M., and Deierlein, G. G. (2013). "Optimal Calibration of Continuum Cyclic Constitutive Model for Structural Steel Using Particle Swarm Optimization,” Journal of Structural Engineering, ASCE, submitted for publication.

Szyniszewski, S., and Krauthammer, T. (2012). "Energy Flow in Progressive Collapse of Steel Framed Buildings," Engineering Structures, 42, 142-153. 